\title{
LAS MAGISTRATURAS ROMANAS COMO EJEMPLO DE CARRERA POLÍTICA.
}

\author{
María José Bravo Bosch \\ Professora titular de Direito Romano na \\ Universidade de Vigo (Espanha) \\ bravobosch@uvigo.es
}

Sumário: Introdução. 1. Os direitos autorais. 2. A lei n 9.610/1998 e o projeto de lei. Considerações finais.

En la antigua Roma, si se quería acceder al más alto cargo de la administración, y por ende, al más alto escalafón político, se tenía que realizar un determinado recorrido, con una jerarquización estricta, que obligaba a comenzar desde abajo en cargos de escaso relieve si se quería llegar a desempeñar el más alto cometido, personificado en la figura del cónsul. Sin embargo, en la actualidad, se accede a los distintos puestos de carácter político sin tener que acreditar un cursus honorum tipificado, pudiendo llegar a lo más alto sin demostrar la cualificación necesaria para el desempeño de tal función. Nuestro propósito en el presente trabajo es poner de relieve como el estamento político de Roma estaba bien organizado, ya que a través de la experiencia adquirida en las distintas magistraturas desempeñadas, los magistrados adquirían las competencias y habilidades necesarias para poder llegar al más alto nivel en Roma.

La administración romana era un ejemplo seguramente debido a la necesidad de poner en orden todos los territorios conquistados, pero eso no empaña el mérito indiscutible de haber establecido un orden necesario que todo ciudadano que quisiese hacer carrera política tenía que respetar.

Lo que vamos a hacer a continuación es un análisis del cursus honorum en la antigua Roma, pero ciñéndonos en concreto a la etapa de aquella Roma imbuida ya por el derecho clásico, pero todavía no sometida al control imperial posterior que hará surgir un nuevo modelo de personal al servicio de la administración, antecedente del moderno funcionario ${ }^{1}$. La perfección

\footnotetext{
1 Vid. al respecto, A. FERNÁNDEZ DE BUJÁN, Derecho público Romano. Recepción, Jurisdicción y Arbitraje, 12 ed. Pamplona, 2009, p. 247-248, cuando afirma: "A partir básicamente del Principado surge la figura del funcionario, si bien dicho término no fue utilizado por la tradición jurídica, quizá porque en contraposición a lo que ocurría con la concepción del magistrado, magistratus, republicano, los funcionarios no tuvieron un carácter jurídico unitario, por lo que se les atribuyeron denominaciones específicas como praefecti, curatores, etc. En todo caso, se trataba de personas que desarrollaban una actividad pública, bien en la Cancillería Imperial o bien en los distintos entes provinciales o locales y que eran titulares de un estatuto caracterizado de modo progresivo por notas como jerarquización, carrera administrativa, respecto a las formas, racionalidad y estabilidad".
} 
alcanzada por Roma en el campo de sus instituciones queda manifiestamente claro en el desarrollo de su propia administración. De este modo, en la época republicana ${ }^{2}$ se repartieron poderes y competencias entre un número no muy elevado de magistrados, a pesar de la ya considerable extensión territorial de Roma, lo que da cuenta de la perfecta regulación de competencias divididas entre las distintas magistraturas creadas al efecto, coordinadas entre sí y jerarquizadas, de acuerdo con el cursus honorum establecido, que marca cuando y cómo se puede acceder a una magistratura determinada. Conscientes del abismo temporal entre la administración del siglo XXI y la de la antigua Roma, asentada desde el siglo III a. C. ${ }^{3}$ creemos necesario abordar el presente estudio, que explicará la necesidad ya desde antiguo de establecer distintos niveles en puestos de trabajo de la administración, y la necesaria promoción para incentivar el esfuerzo perseguido. En otras palabras, la posibilidad de ascender en la carrera administrativa, uno de los mayores acicates a la hora de ingresar en la Administración, ya estaba vigente en el ius honorum accesible a los ciudadanos romanos ${ }^{4}$.

Además, nuestro estudio se centra en el papel desempeñado por los magistrados de Roma, sin ahondar en el cometido de los nuevos administradores nombrados para regir los distintos territorios que se iban incorporando a un imperio romano cada vez mayor. Ya Sila, en el siglo I a.C. crea la diferenciación entre el gobierno de Roma, imperium domi, gestionado por los magistrados, y el de las provincias, imperium militiae ${ }^{5}$, que se asigna a procónsules y propretores, con el

2 C. VARELA, “La evolución histórico-política de Roma”, en $R G D R$ 8, 2007, www.iustel.com, p. 10: "Tras la desaparición de la Monarquía, Roma fue sucesivamente pasando por un gobierno de dictadores, decenviros y tribunos militares hasta conseguir finalmente el establecimiento de una serie de magistrados que, interrelacionándose con el senado y los comicios, se encargaron de la dirección de los aspectos principales de la vida pública".

3 G. POMA, Le istituzioni politiche del mondo romano, Bolonia, 2002, p. 68: "Il sistema magistratuale si formò, nel corso dei secoli, in modo casuale, a seconda delle necessità, senza alcuna legge di istituzione; solo a partire dal III secolo a. C., vennero votate leggi istitutive di magistrature straordinarie o con poteri speciali, che ci offrono il contenuto preciso di tali cariche".

4 A. FERNÁNDEZ DE BUJÁN, Derecho público Romano. Recepción, Jurisdicción y Arbitraje, cit. p. 92, en donde pone en evidencia las diferencias existentes entre patricios y plebeyos, ambos cives romanos, pero siendo los patricios los que gozaban de mayores privilegios: "Las principales reivindicaciones de los plebeyos se presentan en ámbitos diferentes. En el aspecto político la plebe reivindicó el acceso a las magistraturas y a los sacerdocios, ocupadas durante siglos exclusivamente por los patricios. En el aspecto social la plebe luchó por la eliminación de la prohibición del matrimonio (conubium) entre patricios y plebeyos.

5 Vid. al respecto, F. DE MARTINO, Storia della Costituzione Romana, 3, Nápoles, 1973, p. 327: “Per quanto riguarda il conferimento dell'imperium militiae esso fu congiunto al governo delle provincie ed attribuito come imperium proconsulare. Le norme che regolarono questo conferimento furono quelle della lex Sempronia di C. Gracco, la quale disponeva, come sappiamo, che le provincie consolari dovessero essere destinate prima dell'elezione dei consoli e quindi praticamente un anno e mezzo prima del tempo in cui l'ufficio sarebbe stato effettivamente rivestito in conseguenza della lex Cornelia di Silla, la quale stabiliva che l'imperium proconsulare si esercitasse immediatamente dopo la fine dell'anno di carica come console". 
encargo de gobernar y administrar las regiones conquistadas ${ }^{6}$.

Antes de analizar en concreto cada una de las magistraturas republicanas, debemos destacar las características comunes a todas ellas, siendo la gratuidad la primera que merece una cumplida referencia, por cuanto constituye un elemento distintivo de las magistraturas romanas, ajeno totalmente a la realidad de la carrera administrativa actual. Ello significa que las magistraturas al ser cargos honoríficos son gratuitas, sin que el desempeño de las mismas conlleve automáticamente ninguna remuneración ${ }^{7}$. Este principio, observado con gran rigor en el ejercicio del imperium domi - facultad de mando ejercida dentro de la ciudad de Roma-, se debilitó con respecto al imperium militiae $^{8}$-mando militar fuera del pomerium de Roma y superada una milla del mismo-, debido a la costumbre de imponer cuantiosas indemnizaciones para sufragar los viajes y la alimentación a las poblaciones sometidas. Con todo, supone que el acceso al cargo de magistrado no podía ser soportado por familias que careciesen de una posición desahogada económicamente 9 , independientemente de la recuperación posterior de la inversión inicial cuando se le asignase la administración de los nuevos territorios que Roma iba conquistando.

6 C. VARELA, "Los administradores de Roma (desde el origen de la ciudad hasta Justiniano)", en RGDR 7, 2006, www.iustel.com, p. 6-7, al destacar la tripartición de la administración del territorio: "De este modo, la administración del territorio quedó organizada distinguiendo tres zonas diferentes: Roma, regida por magistrados; el resto de Italia, dirigida desde la capital y gestionada fundamentalmente a través del sistema municipal y colonial; y las provincias, para las que se nombraron gobernadores. No obstante, debido a la corta duración de su mandato, estos cargos necesitaron la participación en el gobierno republicano de una institución estable, por lo que el senado se convirtió en el verdadero director de la política estatal (emitía su parecer a través de senatusconsulta, tutelaba la hacienda pública, organizaba el territorio itálico y provincial e intervenía en los asuntos de política exterior e interior)".

7 F. LAMBERTI, Romanización y ciudadanía, Lecce, 2009, p. 29, cuando declara en relación con la gratuidad de las magistraturas: "A esto hay que añadir que la magistratura era en sustancia hereditaria -al menos para las magistraturas superiores- y así se fue trazando desde los primeros años de la república, lo que representó, a lo largo de la república y hasta el final, uno de los principios centrales del funcionamiento de la vida pública".

8 A. BURDESE, Diritto Pubblico Romano, 3 ed. Turín, 1987, p. 62, en donde advierte de los peligros de abusos cometidos por un magistrado: "Per l'esercizio dell'imperium militiae si venne tuttavia affermando la corresponsione, a carico delle popolazioni soggette, di indennità per spese di viaggio, vitto e alloggio incontrate dal magistrato e dal suo seguito: prassi che ebbe la sua maggiore applicazione in ordine al governo delle province, dando luogo a gravi abusi e alla conseguente necessità di organizzare un sistema di repressione con la creazione, nel II secolo a.C., di apposite quaestiones repetundarum".

9 A. VIÑAS, Instituciones politicas y sociales de Roma: Monarquía y República, Madrid, 2007, p. 137-138, en donde pone de relieve la necesidad de una red clientelar, sin que el dinero por sí mismo supusiese el éxito en la carrera hacia la magistratura deseada: "En consecuencia, solamente familias con una economía muy consolidada podrían hacer frente a los múltiples gastos que exigía una campaña electoral bien organizada. No cabía descuidar detalles, pues el tráfico de influencias era frecuente moneda de cambio. Ideología, amistades, clientela familiar y política constituían grupos de presión con los que había que contar y era arriesgado mantenerse alejado de los mismos. Evidentemente, el dinero formaba la energía cuya circulación permitía estrechar lazos, propiciar componendas y facilitar el control de las votaciones". 
Es aquí en donde debemos traer a colación una excepción a la gratuidad señalada, identificada con la figura de los apparitores ${ }^{10}$, que si bien no eran magistrados sino personal subalterno ${ }^{11}$ al servicio de los mismos ${ }^{12}$-ganando estos profesionales de origen liberto un sueldo por ello- suponen el primer paso hacia una administración que remunera a quienes prestan sus servicios en ella ${ }^{13}$.

Otra nota común a todas las magistraturas es la temporalidad, lo que se traduce en la anualidad como plazo para el desempeño de la labor de un magistrado. Ahora bien, en el marco de las operaciones militares, la anualidad quedada suspendida a través de la prorrogatio imperii, que determinaba que los cónsules, pretores y cuestores continuasen ejerciendo su cargo aunque hubiese transcurrido un año, hasta que llegase el sucesor. También los Censores y la magistratura extraordinaria del Dictador se encuentran al margen de este requisito de la anualidad, como veremos al hablar de cada una de ellas.

Como última característica aplicable a las magistraturas en general, debemos citar la colegialidad, elemento imprescindible en el nuevo régimen, que rechazando los excesos de la Monarquía anterior, pretende poner freno a posibles desmanes imponiendo la obligatoriedad del carácter colegiado a todas las

10 TH. MOMMSEN, Staatsrecht, $\mathrm{I}^{3}$, Leipzig, 1887-91, p. 332-371, como estudio básico sobre la figura de los apparitores; contra la opinión de Mommsen, cuando dice que los apparitores estaban sometidos al régimen de la anualidad, A.H.M. JONES, "The Roman Civil Service (Clerical and Sub-clerical Grades)", en JRS 39, 1-2, 1949, p. 38: "Mommsen's assumption that the tenure of apparitores was originally and always in principle annual, like that of the magistrates whom they served, seems to be arbitrary. Apparitores are always described as serving a college of magistrates, and not any individual magistrate. Long tenure appears to have been already the rule in the second century B.C., when L. Petilius, appointed scriba by Q. Petilius as quaestor, is still holding in post when his patron is praetor (Livy, XL, 29)"; acerca de la función de los mismos, J. MUÑIZ COELLO, Empleados y subalternos de la administración romana. I Los scribae, Huelva, 1982, p. 2, valorando positivamente el trabajo de estos empleados subalternos: "Nadie podrá poner en duda la importancia de la infraestructura que amparó la actividad de los magistrados. Pero la misma índole burocrática, soterrada, rutinaria y uniforme de la gestión de las plantillas de apparitores magistratuum les hizo poco propicias al protagonismo en la vida pública diaria.... Tan sólo una historia global y realizada a distancia de los hechos permitiría sopesar la labor de unos, los magistrados, y de otros, los apparitores, en el éxito de aquellos".

11 Vid. al respecto, A. BURDESE, Diritto Pubblico Romano, 3 ed. Turín, 1987, p. 62, en donde nos proporciona la siguiente definición: "personale dipendente, designato col termine generico di apparitores, tra i quali sono viatores, praecones, scribae, nominato per un anno e retribuito".

12 F. DE MARTINO, Storia della Costituzione Romana, I, Nápoles, 1972, p. 409: "Inoltre i consoli hanno un personale dipendente, cui si dà il nome generico di apparitores, che sono viatores, praecones, scribae, nominati per un anno e retribuiti".

13 C. VARELA, "Los derechos de los administradores públicos en Roma", en RGDR 3, 2004, www. iustel.com, p. 2: "Con la llegada del Imperio, el pago por estas prestaciones no sólo se generalizó entre los oficios auxiliares, sino que se extendió a todos los puestos de la Administración. De este modo, la retribución con la que se comenzaba a compensar el esfuerzo desempeñado por los administradores mejoró la capacidad y la formación de las personas que accedían a los distintos cargos". 
magistraturas ${ }^{14}$. O lo que es lo mismo, el destierro de cualquier órgano unipersonal que pueda tomar decisiones que afecten a la administración de Roma. Y como instrumento al servicio de la colegialidad, aparece la intercessio o veto que puede interponer un magistrado de igual o mayor potestas con respecto a su colega. De nuevo nos encontramos con una excepción en este escenario de pluralidad, cual es la figura del Dictador, si bien tan sólo prevista ante una situación excepcional, como magistratura extraordinaria suprema de la República.

A mayor abundamiento, para ser magistrado ${ }^{15}$ se necesitaba una determinada capacidad y proceder a un cierto orden en su ocupación, el conocido cursus honorum $^{16}$, u orden de prelación en el desempeño de las diferentes magistraturas. $Y$ es en relación con esta estructura jerárquica en donde podemos hablar de la potestas ${ }^{17}$, que como dice A. CORBINO, no es, como generalmente se dice, "un" poder, sino la consecuencia del "aver poteri"18, que concede autoridad política sobre la civitas, constituyendo un elemento natural de toda magistratura. Ahora bien, dependiendo de la posición de un magistrado con respecto a los

14 Primero la colegialidad se tradujo en dos magistrados para cada cargo, pero poco a poco fueron aumentando el número de éstos a medida que Roma acrecentaba sus dominios; sirva como ejemplo el testimonio de F. DE MARTINO, Storia della Costituzione Romana, 3, cit. p. 324: "Per quanto riguarda il numero dei magistrati, sappiamo che sotto Silla i questori furono portati a venti ed i pretori ad otto; sotto Cesare rispettivamente a dieci ed a quaranta. L'aumento dei pretori era giustificato dall'esigenza di provvedere al governo delle nuove provincie, quello dei questori per opera di Cesare era ingiustificato e fu di nuovo riportato a venti nell'età augustea. Fra i maggiori magistrati il numero dei consoli non subì mutamenti, salvo le palesi violazioni avvenute durante l'epoca di Pompeo e di Cesare, allorchè il primo divenne consul sine collega, il secondo diede vita a consolati di breve durata e perfino fittizi".

15 G. VAldiTARA, Lo Stato nell'Antica Roma, Catanzaro, 2008, p. 64: "Magistratus è innanzitutto l'ufficio in virtù del quale chi ne è titolare ha il potere e un dovere correlativo di esercitare in nome della res publica romana una serie di funzioni e di compiere una serie di atti efficaci nei riguardi di tutti i cittadini romani. Con l'espressione magistratus si designa poi anche la persona investita di quell'ufficio".

16 Sobre el cursus honorum reordenado por Augusto, E. BADIAN, "Caesar's cursus and the interval's between offices", en JRS 49, 1-2, 1959, p. 88: "It is known that, when Augustus reorganized the cursus honorum, Patricians were given a great advantage: they could move straight from the quaestorship to the praetorship. We do not know whether any gain in time went with this privilege. In any case, custom and practice before long overrode whatever the law on these matters was; and there Patricians -though not they alone- had notable advantages, particularly in the speed of promotion to the consulship".

17 P. CATALANO, "Imperium e Potestas", en Il problema del potere in Roma repubblicana, Sassari, 1974, en donde pone de relieve la dificultad de relacionar imperium y potestas: "Un tentativo rigoroso di dar soluzione al problema dei rapporti fra imperium e potestas potrebbe compiersi soltanto con un completo esame dell'uso che le fonti fanno dei termini magistratus, potestas, imperium, curatio ecc. Mi par certo che un filo logico unisce l'uso pur oscillante. Oscillazioni sul piano tecnico ritroviamo, ad esempio, mettendo accanto: il principio par maiorve potestas plus valeto, per cui non si potrebbe parlare di una parità di potestas fra console e pretore, e il fatto che il pretore è collega del console ed ha un auspicium identico a quello del console", señalando que los conceptos de imperium e potestas son en parte heterogéneos.

18 A. CORBINO, "Istituzioni e ordinamenti della libera res publica", en P. CERAMI/A. METRO/A. CORBINO/ G. PURPURA, Ordinamento costituzionale e produzione del diritto in Roma antica, $2^{\mathrm{a}}$ ed., Nápoles, 2006, p. 57. 
demás, tendrá mayor o menor potestas. Este duelo de potestades se consuma en la par maiorve potestas, que imprime posición de fuerza a quién la tenga; de este modo, el dictador tenía maior potestas que los cónsules, y éstos gozaban de maior potestas sobre los pretores. El censor ocupaba una posición particular, no teniendo maior potestas con respecto a ningún magistrado, aunque tampoco ningún magistratus la tenía sobre él. Entre los magistrados que podríamos denominar minores, cuestores y ediles, no existía sin embargo graduación de la potestas.

El requisito temporal de acceso a las diferentes magistraturas obligaba a dejar transcurrir dos años como mínimo entre una u otra magistratura. Fue establecido por la Lex Villia Annalis, del año 180 a.C. que preveía el acceso en orden ascendente, del siguiente modo: primero se accedería a la cuestura, luego a la edilidad curul, para posteriormente poder acceder a la pretura y finalmente al consulado. Del mismo modo, dicha ley fijó, aunque parece que no de forma vinculante, una edad mínima para acceder a las distintas magistraturas, hasta que Sila fijó con una ley Cornelia de magistratibus en el año 82 a.C. la secuencia de las magistraturas, con los paréntesis necesarios entre las mismas, y la edad mínima para acceder a pretor y cónsul.

Una clasificación conocida de las diferentes magistraturas, la de Mommsen ${ }^{19}$, las divide en ordinarias permanentes, como el consulado, la pretura, la edilidad, la cuestura y el tribunado de la plebe; u ordinaria no permanente, personalizada en la figura del censor. La cualificación de una magistratura como ordinaria viene dada por formar parte normalmente de la constitución republicana para el gobierno de la República, y por su carácter electivo a través de los comitia $^{20}$, renovándose además anualmente. Por lo que respecta a la magistratura extraordinaria, fue creada para necesidades excepcionales de la República, cuyo representante era el dictador.

Otro modo de clasificar a las magistraturas consiste en distinguir las magistraturas mayores de las menores, según los auspicia maiora o minora

19 Staatsrecht, cit. p. 548; también, F. DE MARTINO, Storia della Costituzione Romana 2, Nápoles, 1973, p. 229-230, en donde motiva que la censura deba considerarse como una magistratura ordinaria, aunque no permanente: "Si è sostenuto che la censura apparterrebbe, assieme ai tribuni militum consulari potestate ed alla dittatura, alle magistrature straordinarie. Ma noi abbiamo visto quale fosse la posizione sia della censura, sia dei tribuni militari nel periodo nel quale essi ebbero l'imperium, ed è evidente che tali magistrature non possono essere considerate come straordinarie, al pari della dittatura, alla quale si faceva ricorso solo in casi di emergenza".

20 Vid. al respecto, A. CORBINO, "Istituzioni e ordinamenti della libera res publica", cit. p. 53, cuando declara con respecto a las magistraturas ordinarias: "Esse erano inanzitutto elettive. Competenti a votarne i titolari erano i comitia, che si esprimevano, sotto la presidenza di un console, per centurie, quando si dovevano eleggere magistrati c.d. maggiori e, sotto la presidenza di un pretore, per tribù, quando si trattava di eleggere invece magistrati c.d. minori. Tribuni e edili plebei continuavano ad essere eletti dai concilia plebis, sotto la presidenza di un tribuno". 
que les correspondan ${ }^{21}$. De este modo, son magistraturas mayores las investidas cum imperio junto con la censura, siendo menores la figura de los cuestores, ediles y demás magistrados inferiores. La importancia de esta distinción reside en la forma de elección de dichos magistrados por los comicios, ya que los comicios centuriados eran los encargados de elegir a los magistrados mayores, mientras los comicios por tribus ${ }^{22}$ elegían a los menores.

\section{Refiriéndonos ya en particular a cada una de las magistraturas,} debemos comenzar por el consulado, de rango superior, permanente, ordinaria, integrada por los cónsules ${ }^{23}$, que en número de dos constituían la magistratura más prestigiosa de la civitas romana en la época republicana ${ }^{24}$, siendo además magistrados cum imperio ${ }^{25}$. Gozaban de intercessio o derecho de veto recíproco, lo que incidía sin duda en la responsabilidad en el ejercicio del cargo por parte de cada cónsul. Saber que su colega podía interponer el veto en cualquier momento era una

21 A. VIÑAS, Instituciones políticas y sociales de Roma: Monarquía y República, cit. p. 144, cuando declara que el fundamento de la clasificación de los magistrados en mayores y menores reside en el sistema de los auspicios, añadiendo: "Los auspicios se identifican con un conjunto de ritos puestos en marcha por los augures para averiguar la voluntad de los dioses, mediante los indicios a través de los que se configura el augurio. Los auspicios determinados por los signos que permiten anunciar o presentir un resultado (el augurio) se conciben como actos regulados por el Derecho público y ejecutados con antelación a cualquier acontecimiento con trascendencia e interés para la colectividad cívica. Según el tipo de auspicios que quepa solicitar se establece la distinción entre magistrados mayores y menores. Magistrados mayores son aquellos que, entre sus atribuciones, instan la ejecución de auspicios mayores (auspicia maiora). Magistrados menores son aquellos que sólo pueden solicitar auspicios menores (auspicia minora)".

22 G. POMA, Le istituzioni politiche del mondo romano, cit. p. 60, en donde habla del ámbito competencial de los comitia por tribus: "Erano elettorali, in quanto eleggevano i magistrati minori (questori, edili e tribuni militari), ma anche i tribuni e gli edili plebei, i magistrati straordinari, come i triumviri o i decemviri agrari".

23 En relación con la denominación de cónsul, vid. F. DE MARTINO, Storia della Costituzione Romana, 1, cit. p. 406, n. 1: "Molte delle più antiche testimonianze non si riferiscono evidentemente ai consoli, la cui origine è del 367 , ma alla primitiva magistratura unica donde la distinzione, di cui si trova traccia in età tarda fra praetor maximus o maior e minor: Liv.7, 3, 5... I romani riferivano però logicamente il nome praetor ai consoli e lo consideravano un antico appellativo"; G. VALDITARA, Lo Stato nell'Antica Roma, cit. p. 73: "Il nome più recente di consules deriva dall'acquisizione dell'idea di collegialità ben espressa dalla par potestas di entrambi i praetores e dal reciproco diritto di veto".

24 F. DE MARTINO, Storia della Costituzione Romana 1, cit. p. 406: "I consoli subentrarono, come abbiamo detto, alla primitiva magistratura con collegialità disuguale ed al tribunato militare, che dal 367 non ebbe più il supremo potere. Essi costituivano la maggiore magistratura repubblicana e lo strumento esecutivo del governo senatorio".

25 Vid. al respecto, G. POMA, Le istituzioni politiche del mondo romano, cit. p. 69: "Magistratus (in opposizione a privatus) indica il detentore di un potere di comando, l'imperium (da imperare $=$ comandare); secondo gli autori antichi, l'imperium per eccellenza, quello consolare, era in diretta continuità storica e strutturale con quello dei re, limitato solo dall'annualità. In origine si trattava di una capacità di comando, fondata sulla forza e il prestigio del capo, che, in età repubblicana, assunse un valore giuridico più preciso e divenne patrimonio solo di alcuni magistrati superiori (consoli, pretori, dittatori, decemviri legislativi, tribuni consolari). Implicava il potere di comandare l'esercito e, quindi, di fare leve e di imporre tributi, di esercitare il diritto di vita e di morte (senza possibilità di appello al popolo) sulle truppe", concluyendo que para el comandante victorioso se reservaba la celebración del triunfo y el ser saludado con el título de imperator. 
garantía con respecto a las actuaciones de los cónsules, vigilados mutuamente en el desempeño de sus funciones como magistrados supremos, independientemente del hecho cierto de que cada cónsul gozaba de todo el imperium, que podía ejercer de modo pleno y soberano ${ }^{26}$. Con todo, este poder de veto que se podía oponer al acto de otro cónsul debía interponerse evidentemente antes de que el acto hubiese causado efecto, es decir, en el momento inicial y preparatorio de cualquier decisión que pudiera parecerle errónea a su colega.

Los cónsules tenían un inmenso poder, manifestado en el ejercicio del imperium domi e imperium militiae. Esta diferenciación entre el poder ejercido dentro o fuera de la ciudad se reflejaba en las facultades que tenía en uno u otro ámbito. Así, dentro de la ciudad de Roma (imperium domi), gozaban del ius edicendi, derecho a publicar edictos, el ius agendi cum patribus, o facultad de convocar y presidir el Senado, ius agendi cum populo ${ }^{27}$, poder de convocar la asamblea por tribus, la coercitio como herramienta disciplinaria, y la iurisdictio para poder juzgar, facultad atribuida a los pretores en el año 367 a.C. a través de las Leges Licinia Sextiae, en las cuales se reconoce asímismo la posibilidad de que un plebeyo pueda llegar a ser cónsul ${ }^{28}$, antes reservada a los patricios ${ }^{29}$,

26 F. DE MARTINO, Storia della Costituzione Romana 1, cit. p. 410: "La collegialità nella sua essenza non è l'esercizio del potere da parte dell'intero collegio, ma è l'attribuzione a ciascum collega di tutto il potere e conseguentemente l'esercizio di esso in modo indipendente ed autonomo da parte di ciascuno".

27 A. BURDESE, Diritto Pubblico Romano, cit. p. 65: "Ai consoli spetta poi il diritto di convocare e presiedere i comizi (ius agendi cum populo), sia in sede elettorale presentando l'elenco dei candidati alle elezioni magistratuali e procedendo poi alla acclamazione degli eletti (consoli, pretori, censori, edili, questori: il dittatore è invece direttamente nominato dal console, senza elezione comiziale), sia in sede legsilativa, avanzando proposte di legge; nonché il diritto di convocare il senato (ius agendi cum patribus) per la trattazione di qualsiasi questione".

28 M. HUMBERT, Institutions politiques et sociales de l'antiquité, $4^{\mathrm{a}}$ ed., París, 1991, p. 181, al referirse a las leges Licianiae Sextae, declara : "L'essentiel de la réforme -c'était l'enjeu du dernier combat entre plèbe et patriciat- est dans l'ouverture définitive de la magistrature suprême à la plèbe. Selon 1 eplébiscite et le sénatus-consulte de ratification, un consul sur deux pourra être plébéien"; G. POMA, Le istituzioni politiche del mondo romano, cit. p. 75, en donde destaca las escasas posibilidades de la plebe de acceder al consulado: "Bisogna insistere sull'importanza della gestione delle magistrature a Roma, e in particolare del consolato, che era veramente l'elemento discriminante sul piano sociale. L'acceso al consolato faceva entrare in un altro mondo. Infatti la richezza aveva il suo peso nel favorire la carriera politica, ma non era l'elemento decisivo. Quello che contava per ciascun uomo era la sua dignitas, che era basata anche sulla fama e sul ruolo degli antenati. Se era un nobile, la sua forza e la sua posizione sociale derivavano dal passato della sua casa, dall'appoggio di amici e clienti, dall'onore che veniva dalle cariche. Invece chi, fosse anche il più ricco di Roma, non apparteneva a questa cerchia di famiglie (molto poche, tra le patrizie i Claudi, gli Emili, i Corneli, i Valeri; tra le plebee, i Cecili Metelli, i Porci Catoni, i Licini) ed era quindi homo novus, aveva poche speranze di diventare console, a meno che non fosse adottato da un qualche componente di famiglia importante $o$, come presto avverrà, si conquistasse il potere con la forza delle armi”.

29 Es evidente que los patricios nunca desearon ningún tipo de aperturismo, sino continuar disfrutando de todos su privilegios de forma única, no sólo en relación con las magistraturas, sino en todo lo concerniente a la vida en Roma. Vid. al respecto, M.I. FINLEY, Politics in the Ancient World, Cambridge, 1984, p. 14: "The Roman patriciate was a singularly inelastic order, open to outside recreuits only by the formal adoption of an individual male into a patrician family, a solemn act requiring state approval". 
aunque en realidad las opciones de resultar elegido para tan alta magistratura quedarían reservadas durante largo tiempo a la aristocracia senatorial ${ }^{30}$. Con todo, permanece intacta la competencia de los cónsules para actuar en procedimientos de jurisdicción voluntaria, en los actos procesales, pero no en el núcleo del litigio, ya que dependía del acuerdo de las partes ${ }^{31}$.

Fuera del pomerium ${ }^{32}$ o límite de la ciudad, los cónsules estaba imbuidos de los mayores poderes, puesto que la esfera principal de sus actuaciones se desarrollaba en el ámbito militar. Como afirma A. FERNÁNDEZ DE BUJÁN 33: "Los cónsules eran, ante todo, generales del ejército". Con todo, no era competencia suya la declaración de la guerra, ya que estaba reservada tal facultad a los comicios. La importancia del cometido de los cónsules reside en dirigir la guerra, formar el ejército, imponer tributos por necesidades bélicas, aunque también aquí están sometidos al control del Senado, que puede dar en cualquier momento instrucciones al cónsul de contenido militar.

Como signo de su poder, utilizaban en la ciudad la toga praetexta -blanca y guarnecida por debajo con una tira púrpura-, se sentaban en la sella curulis -silla portátil de marfil, sin respaldo, diferente del trono de un rey- y eran precedidos por una escolta de doce lictores, que portaban las fasces, haz de varas, y fuera de Roma el segur, el hacha para las ejecuciones. Además, tenían la eponimia, o derecho de dar el nombre al año, ya que los romanos carecían de un sistema oficial para indicar el año y por eso adoptaron como guía el nombre de los cónsules del año, uno de los mayores honores reservado a la más alta magistratura. Posteriormente, Augusto encargó la recopilación de los nombres de los cónsules desde el año de la fundación de la República, el 509 a.C, hasta el año 30 a.C. durante su gobierno, en los denominados Fasti Consulares, testimonio vivo de la historia de Roma que aún se conserva.

La siguiente magistratura ordinaria permanente, $y$ en orden

30 F. LAMBERTI, Romanización y ciudadanía, cit. p. 40-41: "Los pertenecientes al círculo restringido de la llamada aristocracia senatorial gozan claramente de un número mayor de privilegios respecto de los ciudadanos romanos 'comunes', provenientes de familias menos antiguas, o de menor importancia política. Entre ellos se da la posibilidad de elegir en el propio seno a los magistrados más altos, sobre todo a los cónsules, el acceso a los sacerdocios, al conocimiento del derecho y al ejercicio de la 'profesión' de iurisperitus, así como a poder disponer de un círculo amplio de clientelas. Incluso otro estamento privilegiado, que se formó a partir de la Segunda Guerra Púnica, como lo es el ordo equester, compuesto de terratenientes, miembros de élites locales naturalizados ciudadanos de Roma, comerciantes y empresarios ricos, banqueros y publicani, dispone de prerrogativas más limitadas frente a la aristocracia senatorial.

31 Cfr. F. DE MARTINO, Storia della Costituzione Romana 1, cit. p. 422.

32 Gell. 13, 14, 1; Varr. 5, 143: quod erat post murum, postmoerium dictum, eiusque auspicia urbana finiuntur.

33 A. FERNÁNDEZ DE BUJÁN, Derecho público Romano. Recepción, Jurisdicción y Arbitraje, cit. p. 134, en donde añade: "Hay numerosas noticias en las fuentes referidas a las campañas militares de los cónsules, los cuales a veces mandaban por separado los cuerpos del ejército y en otras ocasiones se repartían el mando por meses consecutivos o lo sorteaban". 
descendente, la forman los pretores ${ }^{34}$, magistrados superiores dotados de imperium, nombrados en las leges Liciniae Sextiae del 367 a.C $\mathrm{C}^{35}$. colegas minores de los cónsules $^{36}$, al que se le denomina pretor urbano para distinguirlo de los dos cónsules que hasta ese año tenían el nombre de praetores. Su función principal era la administración de justicia ${ }^{37}$, en donde asumió un protagonismo vital para el desarrollo del proceso civil, ya que la primera fase, in iure, se celebra ante él, que sera quién conceda o no la acción solicitada, encauzando el litigio para que en última instancia, en la fase apud iudicem, dicte la sentencia un juez. Esta función judicial pasó pronto a ser privativa en los procesos entre ciudadanos, y la iurisdictio del pretor, con la facultad de promulgar edictos, ius edicendi, pronto llegaría a comprender todas la materias del ius civile. En un primer momento, como señala A. METRO ${ }^{38}$, el pretor tenía asignada la función de velar por la exacta aplicación del ius civile y no la de crear nuevas normas jurídicas, pero progresivamente: "I pretori, che di anno in anno si succedevano nella carica, cominciarono ad acquistare consapevolezza dei propri mezzi ed a svolgere un ruolo molto più incisivo". Poco a poco el pretor, al interpretar el derecho civil, llega a construir un ordenamiento paralelo, un ius praetorium u honorarium, derecho pretorio que corrige y completa las deficiencias del estricto ius civile.

En virtud de su imperium, el pretor urbano publicaba al comienzo de su cargo ${ }^{39}$, su programa jurisdiccional, en el que indicaba las normas por las que

34 G. POMA, Le istituzioni politiche del mondo romano, cit. p. 75: "L'origine della pretura, come quella del consolato, è oscura. L'etimologia del termine (da prae-ire= andare avanti) ha fatto supporre, come si è detto, che il ruolo originario fosse quello, poi assunto dai consoli, di magistrato supremo che guida l'esercito".

35 Vid. al respecto, A. BURDESE, Diritto Pubblico Romano, cit. p. 68: "Il praetor viene creato nel 367 a.C., quale magistratura riservata in origine al patriziato ma alla quale accedono anche i plebei a partire dal 337 a.C.: è collega minor dei consoli che hanno quindi maior potestas rispetto a lui, con pratica attribuzione della specifica competenza di ius dicere inter cives romanos, non disgiunta peraltro dal riconoscimento di un imperium, seppur genericamente subordinato, qualitativamente esteso a ricomprendere le stesse funzioni militari, di governo e amministrative che competono ai consoli".

36 G. VALDITARA, Lo Stato nell'Antica Roma, cit. p. 83: "Il pretore era considerato collega minor dei consoli, rispetto a essi aveva infatti minor potestas il che lo esponeva al potere di avocazione che in qualsiasi momento i consoli potevano esercitare nei suoi confronti”.

37 C. VARELA, Los administradores de Roma (desde el origen de la ciudad hasta Justiniano)", cit. p. 8: "Su misión principal era la de administrar la justicia civil, aunque -de forma subsidiaria y en virtud de su imperium - ejercieron funciones militares y administrativas, convocaron al pueblo para elegir a los magistrados menores y reunieron al senado cuando los cónsules no se encontraban en la ciudad".

38 A. METRO, Le fonti del diritto romano, $2^{\mathrm{a}}$ ed. Messina, 2005, p. 53, concluyendo en p. 54: "In tal modo i magistrati giudiscenti introdussero una serie de integrazioni e di modificazioni al ius civile, ai quali i Romani finirono col riconoscere la natura di un vero e proprio sistema normativo. Questo fu denominato ius honorarium (da honor= carica, magistratura), o anche ius praetorium, data la preponderante posizione del pretore rispetto agli altri magistrati dotati di funzioni giurisdizionali".

39 M. HUMBERT, Institutions politiques et sociales de l'antiquité, cit. p. 215 : "Maîtres de l'organisation de la justice, ils publient chaque année un édit, catalogue des droits dont ils s'engagent à assurer la protection (par l'octroi d'une action en justice) durant l'année de leur charge. Ils présideront naturellement les cours criminelles permanentes, progressivement créées à partir de 149 (de repetundis...)". 
se iba a regir en el año de su mandato, edictum perpetuum, pero podía asímismo publicar un edicto en cualquier otro momento, simpre que las circunstancias lo hiciesen necesario, lo que se conoce como edictum repentinum. Con todo, una lex Cornelia del año 67 a.C. estableció que los pretores debían ejercitar la iurisdictio conforme al edicto publicado al inicio del año: ut praetores ex edictis suis perpetuis ius dicerent.

El pretor urbano, con facultades segregadas de los cónsules, gozaba del ius agendi cum cum populo, poder para convocar a los comicios por tribus para elegir a los magistrados menores, pudiendo también presentar proposiciones de ley, y el ius agendi cum patribus, pero al ser considerado magistrado con imperium inferior al de los cónsules ${ }^{40}$, los sustituye como magistrado supremo en ausencia de éstos de la Urbs, o a petición de ellos o del Senado. Tiene el privilegio de utilizar la toga praetexta, el derecho de sentarse en la sella curulis, e iba precedido por una escolta de seis lictores.

En el año 242 a.C. como consecuencia de la expansión territorial de Roma, y la presencia continua en los litigios de un peregrino, no ciudadano romano como parte litigante frente a un civis, se creó la figura del pretor peregrino ${ }^{41}$, al que se le atribuye la función jurisdiccional en los procesos entre extranjeros y romanos, y de extranjeros entre sí. El praetor peregrinus, al no poder aplicar el ius civile en la resolución de estas controversias, por intervenir en los litigios una parte no ciudadana, tuvo que valerse del poder edictal, y poco a poco fue construyendo un nuevo sistema normativo, fundado sobre principios comunes a todos los pueblos, que fue denominado ius gentium ${ }^{42}$. Este derecho general formado por instituciones

40 T. COREY BRENNAN, The Praetorship in the Roman Republic, Oxford, 2000, p. 58: "His imperium was defined as of the same nature as the consuls', but minus in relation to theirs. As a magistrate with this type of imperium, the praetor could do all that the consuls could do, save the holding of elections of major magistrates in the Centuriate Assembly and the fulfillment of certain religious obligations. All other activities of the consul were open to the praetor, unless a consul stopped him".

41 Vid. al respecto, D.DAUBE, The Peregrine Praetor, en JRS 41, 1-2, 1951, p. 66: "It is universally asumed that the peregrine praetor from the outse had jurisdiction in lawsuits between peregrines, and in lawsuits between a peregrine and a citizen", precisando la etapa en la que tenía tales competencias: "The peregrine praetor in Republican laws and inscriptions invariably figures as the praetor with jurisdiction between peregrines... It is only the laws of the Principate which characterize him as having jurisdiction between peregrines and citizens, though, indeed, this designation occurs from thr first moment, i.e. from Augustus".

42 Gayo 1.1: Omnes populi qui legibus et moribus reguntur, partim suo proprio, partim communi omnium hominum iure utuntur; nam quod quisque populus ipse sibi ius constituit, id ipsius proprium est vocaturque ius civile, quasi ius proprium civitatis ; quod vero naturalis ratio inter omnes homines constituit, id apud omnes populos paraeque custoditur vocaturque ius gentium, quasi quo iure omnes gentes utuntur. Populus itaque Romanus partim suo proprio, partim communi omnium hominum utitur. Quae singula quali sint, sius locis proponemus. 
romanas y no romanas, accesible a los extranjeros ${ }^{43}$, constituye un importante instrumento de evolución y desarrollo del ordenamiento jurídico romano.

Otra magistratura de carácter permanente, de tipo menor, es la representada por los ediles ${ }^{44}$, magistrados romanos creados en época republicana, diferenciados en razón de sus atribuciones en ediles curules y ediles plebis. Los ediles curules constituían originariamente una magistratura colegiada y patricia, fueron creados en el 367 a.C. -fecha de las leges Liciniae Sextiae ya nombradas-, eran elegidos en los comitia tributa, y gozaban de jurisdicción civil en relación con las transacciones realizadas en mercados de esclavos y animales, teniendo además una cierta jurisdicción criminal ${ }^{45}$. Para poder ejercer correctamente la vigilancia de los mercados, publicaban además al inicio de su mandato un edicto, edictum aedilium curulium. Su denominación de "curules" deriva del derecho a sentarse en la sella curulis -también utilizada por los cónsules y pretores que acabamos de ver- que utilizaba en sus traslados por la ciudad, siendo magistrados de rango inferior a los pretores pero superiores a los cuestores. Los ediles de la plebe eran magistrados auxiliares de los tribunos de la plebe, elegidos en los concilios de la plebe, que llegaron a ser asimilados con el tiempo a los ediles curules ${ }^{46}$.

43 A. FERNÁNDEZ DE BUJÁN, Derecho Privado Romano, 2a ed., Madrid, 2009, p. 31: “A los miembros de las comunidades vinculadas o sometidas o que tengan simplemente relaciones comerciales con Roma, se les permite el acceso a negocios del ius civile no formalistas, se crean tipos especiales nuevos, y se aceptan determinadas instituciones y prácticas comerciales de estos pueblos, que no chocan frontalmente con el viejo ius civile. Nace así propiamente un derecho del tráfico jurídico comercial, libre de formas, flexible, basado en la fides, en la lealtad y corrección en el trato, que al final de la República ya se denomina ius gentium, utilizándose la vieja palabra gens, que designaba a los grupos suprafamiliares con un antepasado común, que tan importante papel jugaron en la civitas primitiva".

44 F. DE MARTINO, Storia della Costituzione Romana 1, cit. p. 345-346: "Gli edili erano in numero di due e non furono aumentati, allorchè fu aumentato il numero dei tribuni. Ciò basta ad escludere che la loro posizione iniziale fosse quella di ausiliari dei tribuni, come i questori dei consoli. Nè più attendibile è l'opinione, che gli edili fossero quattro e che in seguito alle leggi Licinie-Sestie due di essi sarebbero divenuti edili curuli; nessun indizio testuale può essere adotto in tal senso".

45 JONES, The Criminal Courts of the Roman Republic and Principate, Oxford, 1972, p. 37, en donde afirma que los ediles, no sólo plebeyos sino también curules: "prosecute for fines only, and usually in less important, non political cases"; L. GAROFALO, Il processo edilizio, Padua, 1989, p. 87, cuando afirma que los tribunos se reservaban para sí la represión de los reos de un delito capital, o delitos de carácter político, mientras que dejaban a la jurisdicción de los ediles: "prima caso per caso, poi in via permanente, il potere di intentare di fronte al concilio plebeo i processi volti alla comminazione delle ammende a carico dei responsabili di illeciti comuni".

46 A. VIÑAS, Instituciones politicas y sociales de Roma: Monarquía y República, cit. p. 161, después de hablar de la identificación de funciones entre ediles curules y plebeyos, añade: "'Se recurre a una fórmula que sintetiza las competencias atribuidas: curatores urbis, annonae, ludorumque solemnium. Se ocupan, por lo mismo, de mantener el orden público, ejercitando extensas labores de vigilancia, al objeto de facilitar el tráfico y preservar la habitabilidad y solidez de las construcciones (cura urbis). Supervisaban, asimismo, los mercados, procurando el adecuado abastecimiento, organización y presidencia de los repartos de alimentos que, con relativa frecuencia, se hacían a precios políticos (cura annonae)", concluyendo que también a ellos les corresponde el control de las fiestas públicas, para prevenir males mayores, lo que se conoce como cura ludorum solemnium. 
Otra magistratura menor, sine imperio, ordinaria y permanente es la de los cuestores, quaestores ${ }^{47}$, cuyo origen se remonta a los años posteriores a la publicación de la ley de las XII tablas, en un principio como meros auxiliares de los cónsules en materia criminal y financiera. En la primera mitad del siglo III a.C., la cuestura ganó su propia autonomía, constituyendo el primer escalón del cursus honorum, el principio para quien quisiera hacer carrera política. Sus atribuciones, de naturaleza sobre todo económica, se dirigen a la administración y el control de los caudales públicos (aerarium populi Romani) así como a ejecutar los cobros y pagos impuestos por los cónsules. El número de los cuestores varió a lo largo de la República, llegando al número de veinte al final de la misma ${ }^{48}$.

Hasta el momento nos hemos referido a las magistraturas integradas en la carrera administrativa dentro de un itinerario normal, si es que se puede denominar así al recorrido integrado en el cursus honorum ínsito en la vida política romana. Con todo, debemos traer a colación otras tres figuras representativas, muy distintas entre sí y de contenido singular, que hacen necesaria una semblanza de cada una de ellas, de modo especial la referida a la censura, que es una magistratura no permanente pero ordinaria.

En primer lugar debemos nombrar a los Tribuni Plebis, tribunos de la plebe ${ }^{49}$, como representantes de la misma, elegidos en los concilios de la plebe en donde se aprobaban los plebiscitos, de contenido mayoritario de derecho privado y judicial, pronto equiparados a las leyes ${ }^{50}$, cuya misión principal consistía

47 G. VALDITARA, Lo Stato nell'Antica Roma, cit. p. 76: "È possibile che si sia trattato di una evoluzione dei quaestores parricidii, magari con riguardo alla gestione del ricavato delle multe irrogate"; sin embargo, A. FERNÁNDEZ DE BUJÁN, Derecho público Romano. Recepción, Jurisdicción y Arbitraje, cit. p. 137: "Aunque tienen el mismo nombre, no parecen estar relacionados estos cuestores con los denominados quaestores parricidii, que estaban encargados del conocimiento y sanción del delito de homicidio", poniendo en duda que los cuestores parricidii tengan algo que ver con los cuestores, más allá del nombre.

48 G. POMA, Le istituzioni politiche del mondo romano, cit. p. 76: "I questori si occupavano di finanze, sorvegliando il tesoro conservato nel tempio di Saturno. Ma non doveva essere questo il loro compito originario, perché il nome (da quarere) indica piuttosto una funzione giudiziaria. Passati da due a quattro, poi a otto, il loro numero accompagnò le multiple necessità di avere questori al fianco dei consoli, in guerra, per gestire la cassa militare e provvedere alle spese, e, in pace, per controllare il regolare versamento delle imposte e la fornitura di truppe da parte delle comunità italiche".

49 Sobre esta figura: NICCOLINI, Il tribunato della plebe, Milán, 1932, passim; GUARINO, La rivoluzione della plebe, Nápoles, 1975; LEVI, Il tribunato della plebe e altri scritti su istituzioni pubbliche romane, Milán, 1978; LOBRANO, Il potere dei tribuni della plebe, Milán, 1982; SERRAO, "Secessione e giuramento della plebe al Monte Sacro", en Diritto@Storia, 7, 2008.

50 F. DE MARTINO, Storia della Costituzione Romana, 2, cit. p. 153-154, en donde declara con respecto a la lex Hortensia del 286 a.C. que equipara los plebiscitos o acuerdos tomados por la plebe en sus asambleas con las leyes: "Abbiamo già ricordato gli avvenimenti nel corso dei quali il dittattore Q. Hortensius fece approvare la legge, secondo cui 'ut eo iure quod plebs statuisset omnes Quirites tenerentur'. Gli argomenti che sono stati addotti per sostenere che la legge ortensia fu la sola, che regolò il tema della validità generale dei plebisciti sono stati anch'essi esaminati a suo luogo, nè vi è motivo di modificare l'opinione allora sostenuta, secondo la legge Publilia del 339 deve ritenerse genuina. Essa appartiene ad un complesso di legge riformatrici, tutte rivolte ad accrescere il potere plebeo, in un tempo nel quale si era pienamente formata la nuova classe dirigente, la nobiltà patrizio-plebea". 
en defender a los plebeyos ${ }^{51}$, siempre en inferioridad con respecto a los patricios ${ }^{52}$. En realidad, no eran magistrados ${ }^{53}$, ni gozaban de imperium, pero sí tenían a su disposición instrumentos como la intercessio o veto contra las decisiones de los magistrados, siempre que juzgasen que perjudicaban a los intereses de los plebeyos $^{54}$. Además, su persona es inviolable ${ }^{55}$, y en virtud de una ley sagrada votada en la asamblea alrededor de los tribunos, se eleva a la categoría de sacrosanta, reconociéndose además la inviolabilidad por parte del ordenamiento jurídico de la civitas, que sanciona con la muerte a cualquier persona que atente contra la vida del tribuno.

En segundo lugar, aunque no menos importante, se encuentra la censura, magistratura colegiada y sine imperio, según la tradición creada ${ }^{56}$ en el

51 Vid. al respecto, A. VIÑAS, Función del tribunado de la plebe, Madrid, 1983, passim; id. Instituciones políticas y sociales de Roma: Monarquía y República, cit. p. 184-185: "La intercessio tribunicia puede paralizar las disposiciones de los magistrados, incluso las dictadas en el transcurso de un proceso civil o penal. Estos procesos manifiestan algo importante: que el tribunado, a pesar de su integración entre los órganos normales de la república, siempre conservó su antiguo estilo combativo a la hora de fiscalizar el poder público y afirmar su posición de defensor de la vida civil".

52 F. DE MARTINO, Storia della Costituzione Romana 1, cit. p 337: "La tradizione conosce quindi un'origine tipicamente rivoluzionaria del tribunato della plebe, sorto dalla necessità della comunità plebea di darsi capi stabili, capaci di guidarla nella lotta contro i patrizi", afirmando que sin embargo la historiografía moderna ha optado por otra teoría, buscando el origen de los tribunos "nell'ordinamento delle tribù territoriali, identificando quindi i tribuni con i capi delle tribù".

53 G. POMA, Le istituzioni politiche del mondo romano, cit. p. 49-50: "I tribuni (due in origine, poi cinque e dieci) non erano magistrati e non avevano imperium; pur tuttavia i loro poteri superavano quelli dei magistrati, poiché essi godevano di diritto di veto (l'intercessio) su ogni atto magistratuale (oltre che interno sugli atti degli altri tribuni) in forza del quale potevano sia opporsi preventivamente alle decisioni dei magistrati sia bloccarle, se già prese. Avevano un potere di coercizione (la coercitio) che li autorizzava ad arrestare ogni cittadino e a portarlo in giudizio davanti alla plebe, comminando multe, esili e forse anche pene capitali".

${ }^{54}$ Con todo, como afirma A. FERNÁNDEZ DE BUJÁN, Derecho público Romano. Recepción, Jurisdicción y Arbitraje, cit. p. 93: "El uso prudente y restringido de este derecho de veto por parte de los tribunos, hizo posible la no paralización de la vida política, que se produciría en caso contrario. Incluso fue frecuente la colaboración entre los tribunos y el Senado, frente a las pretensiones de abuso de poder por parte de otros magistrados".

55 M. HUMBERT, Institutions politiques et sociales de l'antiquité, cit. p. 171 : "L'inviolabilité tribunicienne remonte au berceau du tribunat. La plèbe, en sécession sous les armes, a juré par un serment d'inspiration militaire, par une loi sacrée, de vouer à la mort quiconque (plébéien ou patricien, citoyen ou magistrat) ne respecterait pas l'organisation qu'elle se donnait ou porterait atteinte à la personne et à l'autorité de ses chefs. Cette loi sacrée fit du tribun un personnage lui-même sacré, donc inviolable".

56 Vid. al respecto, A. VIÑAS, Instituciones políticas y sociales de Roma: Monarquía y República, cit. p. 157-158: "Con respecto a la creación de la censura circulan varias versiones. La más verosímil y difundida sería aquella que considera la censura como una magistratura impuesta por la exigencia de liberar a los magistrados supremos de algunas de las múltiples actividades que originariamente tenían atribuidas. En consecuencia, su origen no radica tanto en el interés patricio por incrementar y controlar un mayor número de magistraturas, cuanto en la aplicación del principio de división del trabajo, y la consiguiente necesidad de crear magistrados para ejecutar funciones con relevancia creciente. Funciones que, como el censo, serían realizadas con antelación por los pretores y cónsules de los primeros moemntos republicanos. Aunque el origen de la censura se suele fijar el año 443 a.C., tal afirmación parece más un producto de reconstrucción liviana que dato propiamente histórico". 
año 443 a.C. en un principio reservada para los patricios, aunque a partir del año 351 a.C. es accesible también a los plebeyos. De escaso relieve en sus comienzos, fue poco a poco creciendo en sus competencias hasta llegar a asumir el control total sobre las costumbres (mores maiorum), el honor y las reglas de conducta que debía observar el pueblo romano, consolidándose como la más alta autoridad moral del Estado romano. Eran elegidos cada cinco años por los comicios centuriados ${ }^{57}$, presididos por un cónsul, e investidos por una lex centuriata, para que durante un periodo de dieciocho meses (de acuerdo con la lex Aemilia del 434 a.C ${ }^{58}$.), confeccionasen el censo ${ }^{59}$, función que finalizaba con una ceremonia religiosa de purificación, lustratio o lustrum, de donde viene la denominación de quinquenio. El procedimiento discurría de la siguiente forma: Los paterfamilias bajo juramento y ante el censor, tenían que realizar una declaración de todos sus bienes y de las personas sometidas a su potestas. De acuerdo con la relación facilitada, los censores procedían con la inclusión de los ciudadanos en las difererentes centurias y tribus. Clasificación de enorme importancia, por cuanto de ella se derivaba la determinación del pago de los impuestos ${ }^{60}$ y se conocía a la población para poder incluirla ordenadamente en la estructura militar, tan importante en la vida romana de entonces.

De modo paralelo a la realización del censo se sometía a juicio la conducta de los cives en su vida pública y privada. La disciplina militar, el respeto a los mores maiorum, el comportamiento moral, podían conllevar una anotación

57 F. LAMBERTI, Romanización y ciudadanía, cit. p. 23: "Los comicios centuriados se reúnen para la elección de magistrados mayores, para la promulgación de leyes de contenido político o de bello indicendo y para las decisiones en tema de juicios capitales (provocatio ad populum). El sistema está estructurado de tal modo que en primer lugar acceden al voto las centurias de equites, en segundo lugar las de los pertenecientes a la primera clase y, después, una por una y de mayor a menor importancia las clases sucesivas: si existe acuerdo político, dado que las centurias de caballeros y las de la primera clase constituyen ya la mayoría en conformidad con la cantidad de votos necesarios en la asamblea, a menudo no es necesario el parecer de las clases sucesivas".

58 Vid. al respecto, F. DE MARTINO, Storia della Costituzione Romana 1, cit. p. 326-327, en donde se refiere a las diferencias doctrinales con respecto a esta datación: "I moderni hanno criticato la tradizione; alcuni hanno posto l'origine della censura nel 434, anno in cui una lex del dittatore $M$. Aemilius Mamercus (lex Aemilia de censura minuenda) avrebbe limitiato a diciotto mesi la durata dell'ufficio; altri hanno invece sostenuto che la lex Aemilia sia del 366 e che essa abbia introdotto la censura come magistratura autónoma. La prima opinione è possibile; la seconda è da respingere".

59 C. VARELA, El estatuto jurídico del empleado público en Derecho Romano, Madrid, 2007, p. 72, en donde afirma que los censores: "durante los primeros dieciocho meses de cada lustro, se dedicaban fundamentalmente a la elaboración del censo, la elección de los senadores y la administración y cuidado del patrimonio estatal (ager publicus, edificios, vías y obras públicas)".

60 F. LAMBERTI, Romanización y ciudadanía, cit. p. 26: "El pertenecer al sistema censitario, se decía, es idóneo entre otras cosas al pago de los impuestos. El ciudadano romano asume sobre sí -en proporción al censo- ganancias, pero también bastantes obligaciones. Esa es la cuestión: someterse a los impuestos indirectos -como lo es la tasa sobre la manumisión (que asciende al 5\% del valor de cada esclavo liberado), introducida en el 357 a.C.-, pero sobre todo estar sujeto a impuestos indirectos, como el tributum - una contribución requerida a cada ciudadano en proporción al censo poseído... caundo por decisión del Senado se atribuye un stipendium alos militares". 
unida al nombre del ciudadano, nota censoria, originar la exclusión del censo de la clase de caballeros, o la inscripción en una clase inferior, o en una tribu de escasa relevancia política. La condena máxima suponía privar a la persona censurada de sus derechos políticos, del ius suffragii y de la posibilidad de resultar elegido. Con todo, transcurridos los cinco años, se podía proceder a confirmar o suprimir las notas realizadas por los anteriores censores.

Por último, una referencia a la Dictadura, magistratura extraordinaria designada en los momentos de peligro interior o exterior. El dictador ${ }^{61}$ asumía de forma temporal la autoridad suprema del Estado en el orden administrativo, judicial y militar, sin limitación y con desaparición del poder colegiado de los cónsules. Su poder no era ejercido generalmente más de seis meses, pero concentraba en sus manos tanto el imperium domi como el imperium militae, al suspenderse las garantías de los ciudadanos, lo que se sobreentiende en aras de la seguridad que debía preservar el dictador. Aunque debía haber desempeñado antes el consulado, no nos parece una institución presente de forma habitual en la carrera administrativa romana, sino una magistratura que se instituía con carácter excepcional, y que concentraba el poder de forma no deseable ni habitual ${ }^{62}$.

Las reglas del orden jerárquico que afectaban a las distintas magistraturas romanas demuestran que poco a poco, quién demostrase estar capacitado para ello, podía llegar al más alto escalafón en la vida pública. Es cierto que su recorrido debía ser sin tacha, y mejor con triunfos y honores en su haber, pero no es menos cierto que la posibilidad de llegar a ser Cónsul, con todo lo que ello suponía, imbuía de coraje a los distintos aspirantes a dicho cargo. La obligatoriedad de trabajar en distintos puestos para poder llegar a decidir en la vida política de la Urbs formaba de la mejor forma posible a los magistrados, lo que demuestra que el orden jerárquico establecido para ello fue una medida acertada.

61 A. BURDESE, Diritto Pubblico Romano, cit. p. 66: "Quanto al dittatore, originariamente denominato magister populi e più di recente dictator forse perché dispone (dictat) senza consultarsi coi colleghi in antitesi alla collegialità consolare, è questi un magistrato supremo probabilmente straordinario sin dall'origine della costituzione repubblicana".

62 Vid. al respecto, A. FERNÁNDEZ DE BUJÁN, Derecho público Romano. Recepción, Jurisdicción y Arbitraje, cit. p. 136: “A fines de la República, la dictadura como magistratura constitucional degenera y se nombran dictaduras sin período de tiempo previamente limitado, que es ya el significado moderno de dictadura. César se hace nombrar dictator perpetuo, lo que no tiene nada que ver con la naturaleza del cargo republicano. Augusto, más sutil, desecha el cargo de dictador y se hace nombrar tribuno de la plebe". 